\title{
OBSERVANCE OF HAND WASHING PROCEDURES PERFORMED BY THE MEDICAL PERSONNEL AFTER THE PATIENT CONTACT. PART ॥
}

\author{
ANNA GARUS-PAKOWSKA ${ }^{1}$, WOJCIECH SOBALA ${ }^{2}$, and FRANCISZEK SZATKO ${ }^{1}$ \\ ${ }^{1}$ Medical University of Lodz, Łódź, Poland \\ Department of Hygiene and Health Promotion, Chair of Hygiene and Epidemiology \\ ${ }^{2}$ Nofer Institute of Occupational Medicine, Łódź, Poland \\ Department of Environmental Epidemiology
}

\begin{abstract}
Objectives: The Centers for Disease Control and Prevention (CDC) as well as the World Health Organization (WHO) state that adequate hand hygiene maintained by medical personnel is an indispensable prerequisite for controlling nosocomial infections. The recommendations of CDC and WHO emphasize the obligation to wash hands after each contact with a patient, after the exposure to a potentially infectious material or upon the contact with objects surrounding the patient. Materials and Methods: The study was performed by quasi-observation among the group of 188 medical staff members (nurses and physicians) working in three selected hospitals of the Łódź Province. The procedure of hand washing/disinfection performed directly after the patient contact according to the recommendations of CDC and WHO was observed. The results were subject to statistical analysis ( $\mathrm{p}<0.05$ ). Results: During $1544 \mathrm{~h}$ of observations, 4101 activities requiring hand washing were recorded. The medical personnel followed the hand hygiene procedures after the patient contact in $26.4 \%$ of the situations that require hygiene according to the guidelines. The level of observance of the hand washing procedures depended significantly on the type of performed activity, profession, degree of workload, index of activity, and time of duty hours. The mean time of hand washing after patient contact was $9.2 \mathrm{~s}$ for physicians and $6.7 \mathrm{~s}$ for nurses. Conclusion: Both the level of observance of hygienic procedures after the contact with patients as well as the time of hand washing are insufficient. There is an urgent need to work out educational programs on maintaining proper hand hygiene for medical personnel.
\end{abstract}

Key words:

Hygiene, Compliance with procedures, Hand washing, Medical personnel

\section{INTRODUCTION}

In today's world, no one doubts that proper hand hygiene of medical personnel is an efficient and the cheapest way to prevent nosocomial infections. Keeping hands clean after contact with patients, potentially infectious material, or polluted environment is a key element in interrupting the transmission of microorganisms. Part I of this paper (Observance of hand washing procedures performed by the medical personnel before the patient contact. Part I. by Garus-Pakowska et al. [1]) explains the social and the hygienic hand washing/disinfection of hands by rubbing. According to the guidelines of the Centers for Disease Control and Prevention of Infectious Diseases in Atlanta (CDC) and the World Health Organization (WHO), social hand washing is mandatory in case of visible stains of dirt or blood, or other body fluids. This procedure is recommended also for the

Received: April 27, 2012. Accepted: January 3, 2013.

Corresponding author: A. Garus-Pakowska, Department of Hygiene and Health Promotion, Chair of Hygiene and Epidemiology, Medical University of Łódź, ul. Jaracza 63, 90-251 Łódź, Poland (e-mail: anna.garus-pakowska@umed.lodz.pl). 
possible or proven exposure to spore-forming pathogens (e.g. Bacillus anthracis, Clostridium difficile). Besides, washing hands with soap and water is required after finishing the job and after using the toilet $[2,3]$.

Hygienic hand washing or hygienic hand disinfection by rubbing is recommended in the following circumstances:

- After performing invasive and nursing procedures, regardless of whether gloves were used or not.

- After contact with blood, body fluids, mucous membranes, broken skin, after wound dressing, after contact with burns and bedsores, if dirt is not visible.

- After contact with the catheters, drains and equipment parts directly in contact with the tissues of the patient.

- After contact with intact skin of the patient, for example, after measuring the heart rate or blood pressure, after lifting a patient, etc.

- After contact with secretions and excretions of the patient and other materials potentially contaminated with germs.

- After contact with one patient and before contact with the next patient.

- In case of contact with a patient, between examinations of different parts of the body characterized by different microbial contamination.

- After contact with inanimate surfaces and objects located in the immediate vicinity of the patient.

The World Health Organization points out that in these situations, simple washing hands with soap and water is required when disinfectants are not available.

All of the recommendations emphasize the necessity to decontaminate the skin of hands after contact with the patient, but also after each use of protective gloves. Hand washing with water and soap should take minimum $15 \mathrm{~s}$, while hand cleaning with disinfectants should take ca 20 to $30 \mathrm{~s} \mathrm{[2-4].}$

The aim of the work was to assess the compliance with the requirement of cleaning/disinfecting hands after each patient contact.

\section{MATERIALS AND METHODS}

The study participants included a group of 188 people (nurses and doctors) subjected to direct quasi-participatory observation. They were employees of three hospitals located in the Łódź region. One surgical ("increased risk") and one conservative (medical care) department were selected for the study in each of the hospitals. Detailed description of the test method has been included in "Observance of hand washing procedures performed by the medical personnel before the patient contact. Part I" [1].

Compliance with hygiene procedures was defined as washing the hands at any time interval with soap and water or antiseptic formulation, or disinfecting the hands by rubbing hand sanitizer immediately after contact with patients, as recommended by the Centers for Disease Control and Prevention in Atlanta and the World Health Organization:

- after patient nursing (bathing, making bed, dressing),

- in the case of visible soiling of hands,

- after performing invasive procedures,

- after wound dressing,

- after handling catheters and medical equipment parts directly in contact with the tissue of the patient,

- after contact with a patient's secretions and excretions, - after using gloves.

The duration of hygiene procedures was measured using an electronic stop-watch Magma 10 (Hanhart GmbH \& Co. KG, Germany). The subjects were not informed what kind of activities were being observed. The Bioethics Committee approved the study protocol (Resolution of the Bioethics Committee, Ref. No. RNN/113/06/KE).

Statistical inference was conducted at the significance level $p<0.05$. We used two-sided tests for the verification of the statistical hypotheses. We used a logistic regression model with random effects for analysis of hygiene procedures for hand washing. In the random effect model we 
used a person as a grouping variable. We used the random effect model to account for the within-person correlation. All statistical analyses were conducted using R statistical package (http://www.r-project.org).

\section{RESULTS}

The study group comprised all employees of the six selected departments of the three hospitals of the Łódź Region (125 nurses and 63 doctors). Further description of the structure of the study groups may be found in the paper by Garus-Pakowska et al. [1].

During the observations, 4101 activities were reported as requiring hand hygiene. For the statistical analysis, 3498 operations were selected which, in accordance with the recommendations of the $\mathrm{CDC}$ and $\mathrm{WHO}$, require observing full hygienic procedure (washing/disinfection of hands and wearing protective gloves).

The analysis of the hand hygiene procedures performed after contact with patients or potentially infectious material in relation to the sum of all observed situations requiring such hygiene procedures showed that medical personnel washed their hands in $26.4 \%$ of circumstances which in accordance with the recommendations required such action.

Although the percentage of compliance with hand hygiene "AFTER" patient contact is still low (26.4\%), the difference relative to hand washing "BEFORE" patient contact $(5.2 \%)$ [1] is statistically significant $(\mathrm{p}<0.001)$ (Table 1).

Table 1. Compliance with hand hygiene "before" vs. "after" contacts with the patient or a possibly infectious material

\begin{tabular}{lcccc}
\hline \multirow{2}{*}{ Hygiene } & \multicolumn{4}{c}{ Hand washing } \\
\cline { 2 - 5 } & \multicolumn{3}{c}{ yes } & \multicolumn{3}{c}{ no } \\
\cline { 2 - 5 } & $\mathrm{n}$ & $\%$ & $\mathrm{n}$ & $\%$ \\
\hline Before the activity & 181 & 5.2 & 3317 & 94.8 \\
After the activity & 929 & 26.4 & 2574 & 73.6 \\
\hline
\end{tabular}

$\mathrm{p}<0.001$.
Adherence to the guidelines regarding hand washing after contact with patients was dependent on the type of the performed activity $(\mathrm{p}<0.001)$. Medical personnel washed their hands most frequently after activities involving contact with the patient's excrements, such as per rectum examination $(75 \%)$ or insertion of a urinary catheter (55.4\%). After performing procedures such as e.g. endoscopy and/or biopsy, the hand washing procedure was performed in less than $46 \%$ of the observed activities. The adherence to the hand washing procedure after contact with blood was less frequent. For example, for blood sampling, the compliance rate was $39.8 \%$. The personnel washed their hands definitely least frequently after measuring blood pressure, physical examination and after patientnursing activities (Table 2).

The compliance with the hand hygiene recommendations was similar for all examined departments (Table 3). It was not dependent on the department character, either. Both in the conservative and the "increased risk" departments, the hand washing frequency was similar (Table 4).

Hygienic behaviors when dealing with the patients or infectious material were more frequent in the case of physicians than nurses. The difference is statistically significant at $\mathrm{p}<0.001$ (Table 5).

The workload defined as the activity index (the number of activities requiring hand hygiene per observation unit) affected the level of compliance with the hygiene recommendations. The more numerous were the activities requiring hand hygiene per unit of time, the less frequently the recommendations were adhered to $p<0.001$ (Table 6).

The index of effective workload (total time devoted to work during the observation unit, including cleaning work, administrative work, etc.) confirmed that the work per time unit was significantly $(\mathrm{p}<0.001)$ associated with lesser personnel compliance with the hand washing requirements after contact with the patients (Table 7). 
Table 2. Compliance with the hand washing procedure after activities requiring hygiene, depending on the activity type

\begin{tabular}{|c|c|c|c|}
\hline \multirow[t]{2}{*}{ Activity } & \multirow{2}{*}{$\begin{array}{l}\text { Activities that require } \\
\text { hand washing (total) } \\
\text { (n) }\end{array}$} & \multicolumn{2}{|c|}{$\begin{array}{l}\text { Hand washing after the activity } \\
\qquad(\%)\end{array}$} \\
\hline & & yes & no \\
\hline Collect blood & 304 & 39.8 & 60.2 \\
\hline Insert/remove cannula & 144 & 31.9 & 68.1 \\
\hline Install/remove drip & 1035 & 22.9 & 77.1 \\
\hline Inject & 627 & 22.8 & 77.2 \\
\hline Perform biopsy/endoscopy & 70 & 45.7 & 54.3 \\
\hline Change wound dressing & 239 & 38.9 & 61.1 \\
\hline Insert urinary catether & 65 & 55.4 & 44.6 \\
\hline $\begin{array}{l}\text { Touch equipment that comes in direct contact with } \\
\text { mucous membranes }\end{array}$ & 82 & 19.5 & 80.5 \\
\hline Perform per rectum examination/enema & 8 & 75.0 & 25.0 \\
\hline Contact with patient's excrements (changing diapers) & 183 & 39.3 & 60.7 \\
\hline Patient nursing (washing) & 576 & 16.1 & 83.9 \\
\hline Record arterial blood pressure & 167 & 2.4 & 97.6 \\
\hline Physical examination of a patient & 441 & 15.1 & 84.9 \\
\hline Feed a patient & 160 & 11.1 & 88.9 \\
\hline
\end{tabular}
$\mathrm{p}<0.001$.

Table 3. Compliance with the hand washing procedure after activities requiring hygiene, depending on the department

\begin{tabular}{lcccc}
\hline & \multicolumn{4}{c}{ Hand washing after the activity } \\
\cline { 2 - 5 } \multicolumn{1}{c}{ Department } & $\mathrm{n}$ & yes & $\mathrm{n}$ & no \\
\cline { 2 - 5 } & & & & \\
\hline Hospital 1 & 145 & 26.1 & 410 & 73.9 \\
surgery department & 246 & 28.6 & 615 & 71.4 \\
$\quad$ medical care department & & & & \\
Hospital 2 & 174 & 28.1 & 445 & 71.9 \\
surgery department & 58 & 30.1 & 135 & 69.9 \\
medical care department & & & & \\
Hospital 3 & 110 & 28.9 & 270 & 71.1 \\
surgery department & 191 & 21.5 & 699 & 78.5 \\
medical care department & & & & \\
\hline
\end{tabular}

$\mathrm{p}=0.65$. 
Table 4. Compliance with the hand washing procedure after activities requiring hygiene, depending on the character of the department

\begin{tabular}{|c|c|c|c|c|}
\hline \multirow{3}{*}{ Character of the department } & \multicolumn{4}{|c|}{ Hand washing after the activity } \\
\hline & \multicolumn{2}{|c|}{ yes } & \multicolumn{2}{|c|}{ no } \\
\hline & $\mathrm{n}$ & $\%$ & $\mathrm{n}$ & $\%$ \\
\hline Medical care & 495 & 25.5 & 1449 & 74.5 \\
\hline Increased risk & 429 & 27.6 & 1125 & 72.4 \\
\hline
\end{tabular}

$\mathrm{p}=0.39$.

Table 5. Compliance with the hand washing procedure after activities requiring hygiene, depending on the profession

\begin{tabular}{|c|c|c|c|c|}
\hline \multirow{3}{*}{ Profession } & \multicolumn{4}{|c|}{ Hand washing after the activity } \\
\hline & \multicolumn{2}{|c|}{ yes } & \multicolumn{2}{|c|}{ no } \\
\hline & $\mathrm{n}$ & $\%$ & $\mathrm{n}$ & $\%$ \\
\hline Doctor & 76 & 53.1 & 67 & 46.9 \\
\hline Nurse & 848 & 25.3 & 2507 & 74.7 \\
\hline
\end{tabular}

$\mathrm{p}<0.001$.

Table 6. Compliance with the hand washing procedure before activities requiring hygiene, depending on the activity index

\begin{tabular}{lccccc}
\hline & \multicolumn{5}{c}{ Hand washing after the activity } \\
\cline { 2 - 5 } & Activity index* & yes & $\%$ & $\mathrm{n}$ & no \\
\cline { 2 - 5 } & 502 & 37.1 & 852 & 62.9 \\
\hline $1-3$ & 280 & 23.7 & 901 & 76.3 \\
$4-6$ & 142 & 14.7 & 821 & 85.3 \\
\hline 6 & & &
\end{tabular}

* The number of activities requiring hand hygiene during an observation unit. $\mathrm{p}<0.001$.

Table 7. Compliance with the hand washing procedure after activities requiring hygiene, depending on the index of effective workload

\begin{tabular}{|c|c|c|c|c|}
\hline \multirow{3}{*}{$\begin{array}{l}\text { Index of effective workload } \\
\qquad(\mathrm{min})^{*}\end{array}$} & \multicolumn{4}{|c|}{ Hand washing after the activity } \\
\hline & \multicolumn{2}{|c|}{ yes } & \multicolumn{2}{|c|}{ no } \\
\hline & $\mathrm{n}$ & $\%$ & $\mathrm{n}$ & $\%$ \\
\hline $1-15$ & 201 & 36.4 & 351 & 63.6 \\
\hline $16-45$ & 541 & 25.9 & 1546 & 74.1 \\
\hline$\geq 46$ & 182 & 21.2 & 677 & 78.8 \\
\hline
\end{tabular}

* The total working time in an observation unit. $\mathrm{p}<0.001$. 
Table 8. Compliance with the hand washing procedure after activities that require it, depending on the time of day

\begin{tabular}{|c|c|c|c|c|}
\hline \multirow{3}{*}{ Time of day } & \multicolumn{4}{|c|}{ Hand washing after the activity } \\
\hline & \multicolumn{2}{|c|}{ yes } & \multicolumn{2}{|c|}{ no } \\
\hline & $\mathrm{n}$ & $\%$ & $\mathrm{n}$ & $\%$ \\
\hline 7-12 a.m. & 543 & 28.2 & 1380 & 71.8 \\
\hline 1-6 p.m. & 194 & 26.4 & 542 & 73.6 \\
\hline 7-11 p.m. & 187 & 22.3 & 652 & 77.7 \\
\hline
\end{tabular}

$\mathrm{p}=0.083$.

Table 9. Time devoted to washing/disinfecting hands after activities that require it

\begin{tabular}{lcccccc}
\hline & \multicolumn{5}{c}{ Hand washing time after the activity (s) } \\
\cline { 2 - 7 } \multicolumn{1}{c}{ Department } & doctors & \multicolumn{3}{c}{ nurses } \\
\cline { 2 - 7 } & mean & median & range & mean & median & range \\
\hline Hospital 1 & & & & & \\
$\quad$ surgery department & 10.3 & 10.8 & $2.30-32.80$ & 5.8 & 4.5 & $1.00-18.30$ \\
$\quad$ medical care department & 10.2 & 9.4 & $4.20-20.73$ & 6.1 & 5.0 & $1.31-22.80$ \\
Hospital 2 & & & & & & \\
$\quad$ surgery department & 8.6 & 7.8 & $2.07-19.42$ & 8.3 & 7.2 & $1.21-35.49$ \\
$\quad$ medical care department & 13.4 & 12.3 & $5.02-24.01$ & 7.5 & 6.0 & $1.04-24.68$ \\
Hospital 3 & & & & & & \\
$\quad$ surgery department & 5.8 & 5.7 & $4.14-7.42$ & 6.2 & 6.0 & $1.18-17.36$ \\
$\quad$ medical care department & 6.2 & 6.1 & $3.15-12.08$ & 6.6 & 6.0 & $1.42-31.64$ \\
Total & 9.2 & 7.4 & $2.07-32.80$ & 6.7 & 5.6 & $1.00-35.49$ \\
\hline
\end{tabular}

During night duty hours, medical personnel tended to comply with the requirement to wash their hands after the activity less frequently than in the afternoon and early morning duty hours. The difference was on the border of statistical significance (Table 8).

Adherence to hand hygiene after activities requiring it did not depend on the extent of cooperation with the personnel of the hospital infection control teams $(p=0.55)$. The compliance with the recommendations was low even in cases where the infection control team assessed the hospital personnel affirmatively.

After the activities requiring it, hand hygiene procedure lasted on average $9.2 \mathrm{~s}$ in case of doctors and $6.7 \mathrm{~s}$ in case of nurses. The mean duration of hand washing after the activities requiring it was $7.5 \mathrm{~s}$ for the personnel of "increased risk" departments and $8.3 \mathrm{~s}$ for the personnel of the remaining departments (Table 9).

\section{DISCUSSION}

Interrupting the transmission of microorganisms is one of the key elements of preventing the spread of microorganisms in the environment. Studies show that the hands of medical personnel are the most important vector of the pathogens in healthcare [5-8]. Hence, hand washing after contact with infectious material is extremely important for maintaining proper hygiene in the hospital environment. Unfortunately, this simple 
hygienic procedure continues to be neglected by the medical personnel.

In the Polish literature of the 80 s, only one report on hygiene-related behavior of medical personnel could be located and it was performed using the participant observation method. The study involved the personnel of intensive care units. The participants were informed about the aim of the study and the heads of the hospital departments rigorously recommended the personnel to wash their hands whenever necessary. In spite of that, per 100 direct contacts with the patients, the personnel were noted to wash their hands only in $37 \%$ of the cases [9]. Our results confirmed that even after performing activities associated with high-risk of infection transmission (changing wound dressings, insertion of a urinary catheter, blood sample collection) the observance of hand hygiene rules was poor. At the same time, we noted that the personnel recognizing their personal risk of contamination was significantly more prone to obey the hand hygiene recommendations after contacts with the patients than before such contacts. These result may indicate that in the application of hygiene procedures, medical personnel take into account their own safety rather than the safety of the patients. Thus, it seems reasonable to believe that the protection against infection is illusory. Observations indicate that and hygiene, as part of safeguarding against infection, in the eyes of medical personnel is intended for the protection of the workers rather than for the safety of the patients.

Studies by Whitby and McLaws carried out in three departments of Princess Alexandra Hospital in Brisbane (Australia) confirm this conclusion. Observations of the nursing personnel revealed differences in hygiene-related behavior depending on the character of the department, but the behavior was also more hygiene-oriented after the contact with the patient than before it. In the department of infectious diseases, the rate of following the hygiene procedures was $67.2 \%$ before and $69.9 \%$ after contact with the patient. In the intensive care unit, the values were $44.3 \%$ and $49.3 \%$, respectively. In the department of internal medicine it was $25.4 \%$ and $27.4 \%$, respectively [10]. In our study we found no differences in the hygiene-related behavior of the personnel depending on the nature of the department. In all departments, the hygiene procedures were neglected to a similar extent. The results of other studies confirm significant differences in compliance with hygiene-related recommendations before and after contact with the patients [11-13]. The extent of compliance with hygiene procedures is affected by the workload. The more activities the employees had to perform to serve the patients in a time unit, the less frequently they washed their hands. Perhaps this is the reason for other authors' conclusion that hygiene procedures were better respected by doctors compared to nurses. It should be noted, however, that it is the nurses that have more contact with the patients, so it is them who are required to wash/disinfect their hands more frequently. The adherence to the recommendations for hand hygiene is at a much lower level than expected. In addition, it appears that even if the hygiene procedures are followed, their effectiveness may be questionable because they are not properly executed. Studies show that hand washing takes on average $8-15 \mathrm{~s}$ [14-16]. This study confirms that the average time for washing hands is much shorter than it is required. After activities requiring hand hygiene, the mean hand washing time was $9.2 \mathrm{~s}$ for doctors and $6.7 \mathrm{~s}$ for nurses.

\section{CONCLUSION}

In view of the presented analysis (very low rate of following the procedures and too short hand washing/disinfecting time), it seems that the compliance with the guidelines is highly insufficient.

Higher workloads cause that the hospital hygiene procedures are more frequently neglected. Hand hygiene 
procedures are more frequently disregarded in the afternoon and at night than during the morning duty shifts. Hand washing/disinfection time is on the average twice shorter than recommended.

Urgent need to encourage proper hospital hygiene behaviors among nurses and doctors has been found to be necessary.

\section{REFERENCES}

1. Garus-Pakowska A, Sobala W, Szatko F. Observance of hand washing procedures performed by the medical personnel before the patient contact. Part I. Int J Occup Med Environ Health 2013;26(1):113-21.

2. Boyce J, Pittet D. Guideline for hand hygiene in healthcare settings: Recommendations of the Healthcare Infection Control Practices Advisory Committee and the HICPAC/SHEA/ APIC/IDSA Hand Hygiene Task Force. Am J Infect Control 2002;30:S1-46.

3. Pittet D, Allegranzi B, Boyce J. The World Health Organization Guidelines on Hand Hygiene in Health Care and Their Consensus Recommendations. Infect Control Hosp Epidemiol 2009;30(7):611-22. DOI: 10.1086/600379.

4. Heczko P, Wójkowska-Mach J. Nosocomial infections. Handbook for infection control teams. Warszawa: Wydawnictwo Lekarskie PZWL; 2009 [in Polish].

5. Pessoa-Silva C, Dharan S, Hugonnet S, Touveneau S, PosfayBarbe K, Pfister R, Pittet D. Dynamics of bacterial hand contamination during routine neonatal care. Infect Control Hosp Epidemiol 2004;25(3):192-7. DOI: 10.1086/502376.

6. Pittet D, Hugonnet S, Harbarth S, Mourouga P, Sauvan V, Touveneau S, et al. Effectiveness of a hospital-wide programme to improve compliance with hand hygiene. Lancet 2000;356(9238):1307-12. DOI: 10.1016/S0140-6736(00)02814-2.

7. Rosenthal V, Guzman S, Safdar N. Reduction in nosocomial infection with improved hand hygiene in intensive care units of a tertiary care hospital in Argentina. Am J Infect Control 2005;33(7):392-7.
8. Lindsay Grayson M, Jarvie L, Martin R, Johnson P, Jodoin M, McMullan C, et al. Significant reductions in methicillin-resistant Staphylococcus aureus bacteraemia and clinical isolates associated with a multisite, hand hygiene culturechange program and subsequent successful statewide roll-out. Med J Aust 2008;188(11):633-40.

9. Kędzia W, editor. Prevention and control of hospital infections. Poznań: Wydawnictwo Uczelniane AM im. K. Marcinkowskiego w Poznaniu; 1989 [in Polish].

10. Whitby M, McLaws M. Handwashing in healthcare workers: accessibility of sink location does not improve compliance. J Hosp Infect 2004;58(4):247-53. DOI: 10.1016/j. jhin.2004.07.024.

11. Arenas M, Sánchez-Payá J, Barril G, Garcia-Valdecasas J, Gorriz J, Soriano A, et al. A multicentric survey of the practice of hand hygiene in haemodialysis units: factors affecting compliance. Nephrol Dial Transplant 2005;20(6):1164-71. DOI: 10.1093/ndt/gfh759.

12. Lankford M, Zembower T, Trick W, Hacek D, Noskin G, Peterson L. Influence of role models and hospital design on hand hygiene of health care workers. Emerg Infect Dis 2003;9(2):217-23. DOI: 10.3201/eid0902.020249.

13. Laustsen S, Lund E, Bibby M, Kristensen B, Thulstrup A, Moller J. Cohort study of adherence to correct hand antisepsis before and after performance of clinical procedures. Infect Control Hosp Epidemiol 2009;30(2):172-8. DOI: $10.1086 / 593206$.

14. Kramer A, Rudolph P, Kampf G, Pittet D. Limited efficacy of alcohol-based hand gels. Lancet 2002;359(9316):1489-90. DOI: 10.1016/S0140-6736(02)08426-X.

15. Kuzu N, Özer F, Aydemir S, Yalcin AN, Zencir M. Compliance with hand hygiene and glove use in a university-affiliated hospital. Infect Control Hosp Epidemiol 2005;26(3):312-5. DOI: $10.1086 / 502545$.

16. Meengs M, Giles B, Chisholm C, Cordell W, Nelson D. Handwashingfrequencyinanemergencydepartment.AnnEmerg Med 1994;23(6):1307-12.

This work is available in Open Access model and licensed under a Creative Commons Attribution-NonCommercial 3.0 Poland License - http://creativecommons.org/ licenses/by-nc/3.0/pl/deed.en. 